\title{
ARTÍCULOS
}

\section{Niveles de glomalina y su relación con características químicas y biológicas del suelo (andisol) en un relicto de bosque nativo del sur de Chile}

\author{
Levels of glomalin and their relation with soil chemical and biological \\ soil (andisol) characteristics in a relic of native forest of southern Chile
}

\author{
Alex Seguela, Rosa Rubio ${ }^{b}$, Rubén Carrillo ${ }^{a}$, Alejandro Espinosa ${ }^{a}$, Fernando Borie ${ }^{\text {b* }}$ \\ aUniversidad de La Frontera, Facultad de Ciencias Agropecuarias y Forestales, Temuco, Chile. \\ *Autor de correspondencia: bUniversidad de La Frontera, Facultad de Ingeniería, Ciencias y Administración, casilla 54-D, \\ Francisco Salazar 0845, Temuco, Chile, tel.- fax: 45-325440, fborie@ufro.cl
}

\begin{abstract}
SUMMARY
In forest ecosystems the arbuscular mycorrhizal fungi (AMF) play an important role in the carbon accumulation by a glicoprotein production named glomalin that participate in the soil aggregate stability. Therefore, the aim of this study was to quantify the glomalin content of an andisol of southern Chile under adult and mixed forest and to determine the relationships with fungal and soil chemical characteristics. The study was at two slopes and exposition (NE and SW). The forest vegetation was principally dominated by species that develop ectomycorrhiza, but the underforest species, shrubs and climbers, developed arbuscular mycorrhiza with high glomalin production capacity and with amounts higher than those determined in agroecosystems for the same area. Glomalin concentration in the upper horizon ranged between 44.2 and $46.1 \mathrm{mg} \mathrm{g}^{-1}$ representing between 8.9 and $10.4 \%$ of the total soil carbon, decreasing their content as depth increased. The slope and exposition type influenced glomalin content both, total and easily extractable. Therefore, NE with smooth slope presented the major content of total glomalin, while SW with sharp slope showed high levels of easily extractable glomalin. Total glomalin showed close relationships with the spores AMF $(r=0.84, P<0.001)$ and with soil organic matter $(r=0.83$, $P<0.001)$. Data obtained in this study suggest that it is necessary to preserve the forest ecosystems for keeping up the mycorrhizal potential and reinforce the statement that glomalin can be an important carbon sink contributing to soil carbon retention.
\end{abstract}

Key words: arbuscular mycorrhizal fungi, glomalin, carbon storage, andisol.

\section{RESUMEN}

En ecosistemas forestales, los hongos micorrícico-arbusculares (HMA) juegan un rol importante en la acumulación de carbono debido a la producción de una glicoproteína denominada glomalina que participa en la estabilidad de los agregados de suelo. Por lo tanto, el objetivo del estudio fue cuantificar el contenido de glomalina en un andisol del sur de Chile bajo bosque mixto adulto y estudiar las relaciones con características fúngicas y químicas del suelo, bajo dos pendientes y exposiciones (NE y SO). La vegetación forestal estuvo dominada principalmente por especies que forman ectomicorrizas, pero especies acompañantes, arbustos y trepadoras presentaron micorrizas arbusculares capaces de producir altos niveles de glomalina, superiores a los de agroecosistemas de la misma área. La concentración de glomalina en el suelo superior $(0-10 \mathrm{~cm}$ ) fluctuó entre 44,2 y 46,1 mg g-1, representando entre 8,9 y 10,4\% del carbono total del suelo, disminuyendo sus contenidos a mayor profundidad. Así, NE con inclinación suave presentó mayor contenido de glomalina total, mientras que SO, con pendiente abrupta, tuvo elevados niveles de glomalina fácilmente extraíble. La glomalina total mostró estrecha relación con las esporas de HMA $(\mathrm{r}=0,84 ; P<0,001)$ y materia orgánica $(\mathrm{r}=0,83 ; P<0,001)$. Los datos obtenidos en este estudio sugieren la necesidad de preservar los ecosistemas forestales para mantener el potencial micorrícico y refuerzan la aseveración de que la glomalina puede ser un reservorio de carbono, contribuyendo a la retención de $\mathrm{CO}_{2}$ atmosférico.

Palabras clave: hongos micorrícico-arbusculares, glomalina, almacenamiento de carbono, andisol.

\section{INTRODUCCIÓN}

A nivel mundial, los bosques cumplen un rol fundamental en la retención de carbono (C) al almacenar más del 40\% del carbono terrestre (Jandl 2001), por lo cual poseen un enorme potencial para mitigar el cambio climático global. Aunque en
Chile se han realizado algunos estudios para determinar la acumulación de carbono en ecosistemas forestales, ellos no han incluido a los hongos micorrícico-arbusculares (HMA) como componentes de tal retención.

Los HMA son microorganismos simbiontes ubicuos que participan activamente en la captación de nutrientes 
para las especies vegetales (Jeffries et al. 2003), protegiendo las raíces frente a la acción de patógenos (Newsham et al. 1995), mejorando la tolerancia a la fitotoxicidad por aluminio (Borie y Rubio 1999), manganeso (Mendoza y Borie 1998), metales pesados (Pawlowska y Charvat 2004), déficit hídrico (Ruíz-Lozano y Azcón 1995) e incidiendo significativamente en el establecimiento, desarrollo y por ende en la diversidad de especies de plantas (van der Heijden et al. 1998). Por otra parte, la simbiosis induce cambios fisiológicos al aumentar la tasa fotosintética, redistribuyendo el carbono fijado, con mayor proporción en las raíces. De este modo, las plantas micorrizadas transfieren 6-12\% adicional del carbono total fijado en comparación con plantas no micorrizadas, lo que representa un aumento notable en la disponibilidad por actividad microbiana (Lynch y Whipps 1990).

Además, los HMA producen una glicoproteína insoluble de elevado peso molecular denominada glomalina que se ha encontrado en suelos de diversos ecosistemas y con relativa abundancia (Rillig et al. 2001, 2003, Borie et al. 2006), teniendo una vida media de 6 a 42 años, lo cual conlleva una lenta velocidad de degradación que depende del suelo de origen (Rillig et al. 2001). La estructura química aún se desconoce, aunque se ha informado que está compuesta por un complejo de aminoácidos, carbohidratos y hierro $(<5 \%)$ (Nichols 2003). Además, contiene un alto porcentaje de carbono (27,9-43,1\%) (Rillig et al. 2003), llegando incluso a representar hasta un 52\% del carbono total en suelos orgánicos (Schindler et al. 2007), el cual es incorporado directamente al suelo mediante descomposición de los propágulos fúngicos. Sin embargo, la glomalina sería más importante en la retención de carbono por su alta recalcitrancia y capacidad para formar agregados estables (Rillig et al. 1999); así, suelos con alta agregación presentan mayor resistencia a las fuerzas erosivas con mejor intercambio gaseoso y capacidad de almacenamiento de agua y nutrientes, simultáneamente con poseer micrositios heterogéneos (Blevins et al. 1984).

Por otra parte, los bosques de la Depresión Intermedia de Chile corresponden principalmente a renovales (bosque de segundo crecimiento) con algunos bosquetes remanentes originales pertenecientes a la formación roble (Nothofagus obliqua [Mirb.] Oerst.) - laurel (Laurelia sempervirens [R. et P] Tul.) - lingue (Persea lingue [R. et P.] Nees ex Kopp.) que permanecen inalterados (Donoso 1995). La estructura es multietánea, multiestratificada, con individuos de roble dominantes y emergentes de grandes diámetros (Martínez 1999) pertenecientes al tipo forestal Roble-Raulí-Coigüe (Donoso 1981). Una muestra de este tipo de bosques y de lo que existía antiguamente en la Región de La Araucanía lo constituye el predio Rucamanque, ubicado en una zona de transición entre bosques siempreverdes del sur y esclerófilos de la región mediterránea central que lo convierten en una zona ecotonal de gran relevancia ecológica con vegetación única dentro del país (Salas 2001).
A nivel nacional existen escasos antecedentes de los HMA relacionados con el contenido de glomalina para distintas condiciones edáficas o climáticas; por lo tanto, el objetivo de este estudio fue cuantificar en un andisol del predio Rucamanque bajo bosque mixto adulto del tipo forestal Roble - Raulí - Coigüe los contenidos de glomalina para relacionarlos con parámetros micorrícicos y químicos del suelo.

\section{MÉTODOS}

Área de estudio, muestreo de suelo y raíces. El estudio se realizó en el predio Rucamanque (435,1 ha) situado en los 38³9' S y 72³5' O, comuna de Temuco (Región de La Araucanía, Chile). La altitud media del predio es de 376 $\mathrm{m}$, con dos tipos de suelos dependiendo del nivel altitudinal: trumaos y suelos de transición entre trumaos y rojo arcillosos (serie Nielol con capacidad de uso VII e). Estos suelos poseen menos de un metro de profundidad, tienen una textura limosa y alto grado de materia orgánica y de permeabilidad (Frank y Finckh 1998) con una densidad aparente de 0,5 $\mathrm{g} \mathrm{cm}^{-3}$ (Bürgmann 1998). El predio posee una topografía de relieve monticulado e irregular, por lo que las laderas cubiertas por el bosque presentan pendientes variadas en extensión e inclinación. El clima es templado húmedo, con una precipitación anual de $1.400 \mathrm{~mm}$. La temperatura media es de $12{ }^{\circ} \mathrm{C}$, con uno o dos meses de sequía en verano (Di Castri y Hajek 1976).

Por las características edáficas de andisol se seleccionó dentro del predio Rucamanque el Rodal № 8 (18 ha) que corresponde a un bosque mixto adulto de olivillo (Aextoxicon punctatum R. et P.), roble, ulmo (Eucryphia cordifolia Cav.), laurel y lingue perteneciente al tipo forestal Roble-Raulí-Coigüe, subtipo remanentes originales (Donoso 1981). El bosque presenta una estructura multietánea y multiestratificada, con una densidad promedio de 680 árboles ha ${ }^{-1}$ y $97 \mathrm{~m}^{2} \mathrm{ha}^{-1}$ de área basal; en el bosque adulto el roble está presente exclusivamente en el estrato emergente, alcanzando alturas entre 42 y $53 \mathrm{~m}$ y con un diámetro medio cuadrático (DMC) superior a $85 \mathrm{~cm}$ (Salas 2001). Dentro de dicho rodal se seleccionó un sitio con exposición noreste (NE) ubicado en el límite superior del predio, a una altitud de $504 \mathrm{~m}$ (coordenadas UTM 0709496-5719595 determinadas con GPS Garmin 75 con una precisión en XY de $100 \mathrm{~m}$ ) con $30 \%$ de pendiente (medida con clinómetro Suunto), y otro sitio con exposición suroeste (SO) situado a $460 \mathrm{~m}$ s.n.m., con una pendiente abrupta de 60\% (coordenadas UTM 0709250-5719282), ambos presentando el mismo tipo de bosque.

El Rodal $\mathrm{N}^{\circ} 8$ de Rucamanque presenta una variada comunidad de especies arbóreas, arbustivas, trepadoras y de helechos (cuadro 1). El dosel superior está compuesto principalmente por olivillo, roble, ulmo, laurel, lingue, tepa (Laureliopsis philippiana [Looser] Schodde) y tineo (Weinmannia trichosperma Cav.). La regeneración está 
compuesta principalmente por especies tolerantes y semitolerantes como tepa, olivillo y lingue; además, existen otras especies acompañantes como avellano (Gevuina avellana Mol.), avellanillo (Lomatia dentata [R. et P.]) y mañío de hojas largas (Podocarpus saligna D. Don). Adicionalmente se presenta un denso sotobosque dominado principalmente por quila (Chusquea quila Kunth), con una gran diversidad de arbustos, trepadoras y especies herbáceas.

En septiembre del año 2006 se realizó el muestreo de suelo a dos profundidades: 0-10 y $10-20 \mathrm{~cm}$, delimitándose una parcela de $25 \mathrm{~m}^{2}$ en cada sitio de estudio y removiendo la capa de mantillo. Para cada profundidad se extrajeron con barreno cinco muestras compuestas, las que se obtuvieron a partir de cinco submuestras aleatorias en cada una de las parcelas, con un total de 20 muestras compuestas. Simultáneamente, con el muestreo de suelos se caracterizó la composición florística con su respectiva clasificación taxonómica de las especies de acuerdo a Marticorena y Quezada (1985). Además, en cada área de la ladera se muestrearon raíces finas $(<20 \mathrm{~mm}$ de diámetro) de tres o más individuos de cada especie a una distancia de $1 \mathrm{~m}$ alrededor del tronco excavando hacia el exterior, tanto en árboles jóvenes como adultos, a una profundidad de 15 a $30 \mathrm{~cm}$, mientras que para arbustos y herbáceas a una profundidad de 0 a $20 \mathrm{~cm}$, con la finalidad de establecer presencia o ausencia de HMA en las distintas especies vasculares.

Análisis microbiológicos. Se cuantificaron los niveles de glomalina total (GT), fracción más recalcitrante de la glicoproteína y glomalina fácilmente extraíble (GFE) o fracción más lábil que se encuentra débilmente unida a las partículas del suelo. La GT se determinó mediante extracciones sucesivas con citrato de sodio $50 \mathrm{mM} \mathrm{pH}$ 8,0 en autoclave a $121{ }^{\circ} \mathrm{C}$ por ciclos de 60 minutos hasta desaparición del color pardo-rojizo característico con posterior determinación espectrofotométrica, de acuerdo al método Bradford para proteínas como lo proponen

Cuadro 1. Composición florística del predio Rucamanque.

Flora found at Rucamanque forest.

\begin{tabular}{|c|c|c|c|}
\hline Tipo de planta & Nombre científico & Nombre vernáculo & Familia \\
\hline Árbol & $\begin{array}{l}\text { Aextoxicon punctatum } \mathrm{R} . \text { et } \mathrm{P} . \\
\text { Dasyphyllum diacanthoides (Less.) Cabrera } \\
\text { Eucryphia cordifolia Cav. } \\
\text { Gevuina avellana Mol. } \\
\text { Laurelia sempervirens (R. et } \mathrm{P} \text { ) Tul. } \\
\text { Laureliopsis philippiana (Looser) Schodde } \\
\text { Lomatia dentata (R. et } \mathrm{P} \text {.) } \\
\text { Lomatia ferruginea (Cav.) R. Br. } \\
\text { Luma apiculata (DC.) Burret } \\
\text { Nothofagus obliqua } \text { (Mirb.) Oerst. } \\
\text { Persea lingue (R. et } \text { P.) Nees ex Kopp. } \\
\text { Podocarpus saligna } \text { D. Don } \\
\text { Weinmannia trichosperma Cav. }\end{array}$ & $\begin{array}{l}\text { Olivillo } \\
\text { Trevo } \\
\text { Ulmo } \\
\text { Avellano } \\
\text { Laurel } \\
\text { Tepa } \\
\text { Avellanillo } \\
\text { Fuinque } \\
\text { Arrayán } \\
\text { Roble } \\
\text { Lingue } \\
\text { Mañío de hojas largas } \\
\text { Tineo }\end{array}$ & $\begin{array}{l}\text { Aextoxicaceae } \\
\text { Asteraceae } \\
\text { Eucryphiaceae } \\
\text { Proteaceae } \\
\text { Monimiaceae } \\
\text { Monimiaceae } \\
\text { Proteaceae } \\
\text { Proteaceae } \\
\text { Myrtaceae } \\
\text { Fagaceae } \\
\text { Lauraceae } \\
\text { Podocarpaceae } \\
\text { Cunoniaceae }\end{array}$ \\
\hline Arbusto & $\begin{array}{l}\text { Azara microphylla Hook. f. } \\
\text { Chusquea quila Kunth } \\
\text { Myrceugenia planipes (Hook. et Arn.) Berg. } \\
\text { Pseudopanax laetevirens (Gay) Harms. } \\
\text { Rhamnus diffusus Clos. }\end{array}$ & $\begin{array}{l}\text { Aromo de hoja pequeña } \\
\text { Quila } \\
\text { Picha-picha } \\
\text { Sauco } \\
\text { Arrayán negro }\end{array}$ & $\begin{array}{l}\text { Flacourtiaceae } \\
\text { Gramineae } \\
\text { Myrtaceae } \\
\text { Araliaceae } \\
\text { Rhamnaceae }\end{array}$ \\
\hline Enredadera & $\begin{array}{l}\text { Cissus striata } \mathrm{R} . \text { et } \mathrm{P} . \\
\text { Elytropus chilensis }(\mathrm{A} . \mathrm{DC} \text {.) Muell. Arg. } \\
\text { Lapageria rosea } \mathrm{R} . \mathrm{et} \mathrm{P} . \\
\text { Luzuriaga radicans } \mathrm{R} \text {. et } \mathrm{P} . \\
\text { Mitraria coccinea } \text { Cav. }\end{array}$ & $\begin{array}{l}\text { Voqui rojo } \\
\text { Voqui quilmay } \\
\text { Copihue } \\
\text { Quilineja común } \\
\text { Botellita }\end{array}$ & $\begin{array}{l}\text { Vitaceae } \\
\text { Apocynaceae } \\
\text { Philesiaceae } \\
\text { Philesiaceae } \\
\text { Gesneriaceae }\end{array}$ \\
\hline Helecho & $\begin{array}{l}\text { Blechnum blechnoides Keyserl. } \\
\text { Blechnum hastatum Kaulf. } \\
\text { Hymenoglossum cruentum (Cav.) K. Presl } \\
\text { Polypodium feuillei Bertero }\end{array}$ & $\begin{array}{l}\text { Iquide } \\
\text { Quil-quil } \\
\text { Helecho película } \\
\text { Helecho calahuala }\end{array}$ & $\begin{array}{l}\text { Blechnaceae } \\
\text { Blechnaceae } \\
\text { Hymenophyllaceae } \\
\text { Polypodiaceae }\end{array}$ \\
\hline Hierba & $\begin{array}{l}\text { Acaena ovalifolia } \mathrm{R} \text {. et } \mathrm{P} . \\
\text { Nertera granadensis } \text { (Mutis ex L.f.) Druce } \\
\text { Osmorrhiza chilensis } \text { H. et A. } \\
\text { Urtica urens } \text { L. }\end{array}$ & $\begin{array}{l}\text { Cadillo } \\
\text { Coralito del monte } \\
\text { Cacho de cabra } \\
\text { Ortiga común }\end{array}$ & $\begin{array}{l}\text { Rosaceae } \\
\text { Rubiaceae } \\
\text { Umbelliferae } \\
\text { Urticaceae }\end{array}$ \\
\hline
\end{tabular}


Wright y Upadhyaya (1996) y con las modificaciones realizadas por Morales et al. (2005) para andisoles. En ambos sitios, para las muestras en superficie se necesitaron cinco extracciones y tres en profundidad. Para la GFE se realizó una extracción con citrato de sodio $20 \mathrm{mM} \mathrm{pH}$ 7,0 con autoclavado a $121{ }^{\circ} \mathrm{C}$ por 30 minutos (Wright y Upadhyaya 1996, Morales et al. 2005).

Análisis de propágulos HMA. Para estudiar el potencial de inóculo HMA se evaluó la colonización por HMA en las raíces de los hospederos, el número de esporas en el suelo, la longitud de micelio fúngico total y el que permanece activo. Para determinar la presencia o ausencia de HMA se cortaron trozos de raíces de aproximadamente $1 \mathrm{~cm}$ de longitud y se decoloraron con solución de $\mathrm{KOH}$ o $\mathrm{H}_{2} \mathrm{O}_{2}$ en caliente, se neutralizaron con $\mathrm{HCl}$ y finalmente se tiñeron con azul de tripán (Phillips y Hayman 1970). La presencia de estructuras fúngicas como arbúsculos y vesículas (cuando las hubo) se observó con utilización de microscopia óptica. Las esporas de HMA se extrajeron desde el suelo mediante la técnica de tamizado húmedo con posterior decantación a través de tamices $(425 \mu \mathrm{m}-$ $53 \mu \mathrm{m})$ y centrifugación en gradiente de sacarosa para ser cuantificadas en placas de Doncaster bajo una lupa estereoscópica (Sieverding 1991). La longitud de micelio extrarradical se determinó por el método del intercepto de líneas de acuerdo a metodología propuesta por Rubio et al. (2003) para suelos derivados de cenizas volcánicas, previa extracción desde el suelo con glicerina ácida y posterior filtración a través de un sistema de filtración micropore utilizado como medio de tinción. En el caso del micelio total, se utilizó el colorante azul de tripán y para el micelio activo, una solución que contenía iodonitrotretazolium, la que tiñe de rojo las partes activas del hongo.

Análisis químico de los suelos. Se realizaron mediciones de algunas características químicas para determinar la fertilidad de los suelos: a) $\mathrm{pH}$ se midió potenciométricamente con electrodo de vidrio en una suspensión de suelo: agua en relación 1:2,5; b) porcentaje de materia orgánica (MO) se determinó por oxidación con dicromato en medio ácido (Walkley y Black 1934); c) aluminio extraíble se analizó por espectrofotometría de absorción atómica (EAA) previa extracción con solución de acetato de amonio pH 4,8 (Sadzawka et al. 2000) y d) los microelementos hierro, cobre, cinc y manganeso mediante extracción con ácido dietilentriaminopentaacético (DTPA) a pH 7,3 y posterior análisis por EAA (Lindsay y Norvell 1978). También se analizaron distintas fracciones de fósforo (P): P-total por digestión de la $\mathrm{MO}$ con hipobromito de sodio de acuerdo a metodología propuesta por Dick y Tabatabai (1977), P-disponible por extracción con $\mathrm{NaHCO}_{3}$ 0,5 M a pH 8,5 (Olsen y Sommers 1982) y P-orgánico (Po) mediante fraccionamiento del P-húmico y P-fúlvico (Borie y Rubio 2003).
Análisis enzimático de los suelos. La actividad fosfatásica asociada con el suelo se determinó usando p-nitrofenilfosfato (p-NFF) de acuerdo al procedimiento descrito por Tabatabai y Bremmer (1969) con modificaciones informadas por Rubio et al. (1990) para suelos volcánicos con altos niveles de MO.

Análisis estadístico. Para cada variable medida se ensayó homogeneidad de varianzas y posteriormente se realizó una comparación de medias mediante la prueba t de Student; posteriormente estas variables fueron sometidas a análisis de correlación divariada (r Pearson) para estudiar la dependencia lineal entre ellas utilizando el programa JMP 5.01 (SAS). Para todos los casos, el nivel de significancia correspondió a $P<0,05$.

\section{RESULTADOS}

Características microbiológicas. La GT presente en los suelos superficiales de $0-10 \mathrm{~cm}$ no mostró diferencias entre los dos sitios de estudio como consecuencia de las distintas exposiciones $(P=0,365)$. En las muestras más profundas del suelo, entre $10-20 \mathrm{~cm}$, se observó una notable disminución de la glicoproteína especialmente en la posición NE. En la figura $1 \mathrm{~A}$ se puede observar que se encontraron diferencias significativas en los niveles de GT en los suelos de ambos sitios a la profundidad de $10-20 \mathrm{~cm}(P=0,025)$, teniendo la ladera de exposición SO un incremento en el contenido de glomalina de un $41 \%$ con respecto a NE. En la GFE en superficie se observaron diferencias entre los suelos de ambas exposiciones $(P=0,005)$, teniendo la ladera $\mathrm{NE}$ un contenido significativamente menor (figura 1B), con un incremento en SO de un $175 \%$ sobre la ladera NE. A mayor profundidad se mantuvo la misma tendencia que en superficie, con un aumento en el contenido de proteína en SO sobre un $2.500 \%$ respecto a la ladera NE $(P<0,001)$. Al comparar la relación entre la GFE con la GT, la ladera NE presentó sólo un $20 \%$ de GFE entre $0-10 \mathrm{~cm}$, mientras que en profundidad esta relación disminuyó a un 3\%. Por el contrario, en la ladera SO la proteína se encontró mayoritariamente como GFE, correspondiendo al 58\% de la GT en superficie y a un $63 \%$ en profundidad.

$\mathrm{Si}$ se asume que para transformar el carbono orgánico del suelo (COS) a C-glomalínico (C-G) la molécula de glomalina contiene un 32,6\% de carbono en suelos de origen volcánico con especies pertenecientes a la familia Fagaceae $^{1}$; en los suelos superficiales la proporción de C-G en el pool del COS total representa un 10\% para NE y un $9 \%$ para SO. En profundidad la proporción resulta similar pero con un leve incremento de $\mathrm{SO}$ respecto a NE (cuadro 2).

P Etcheverría. 2007. Universidad de La Frontera. Programa de Doctorado en Ciencias de Recursos Naturales. Comunicación personal. 

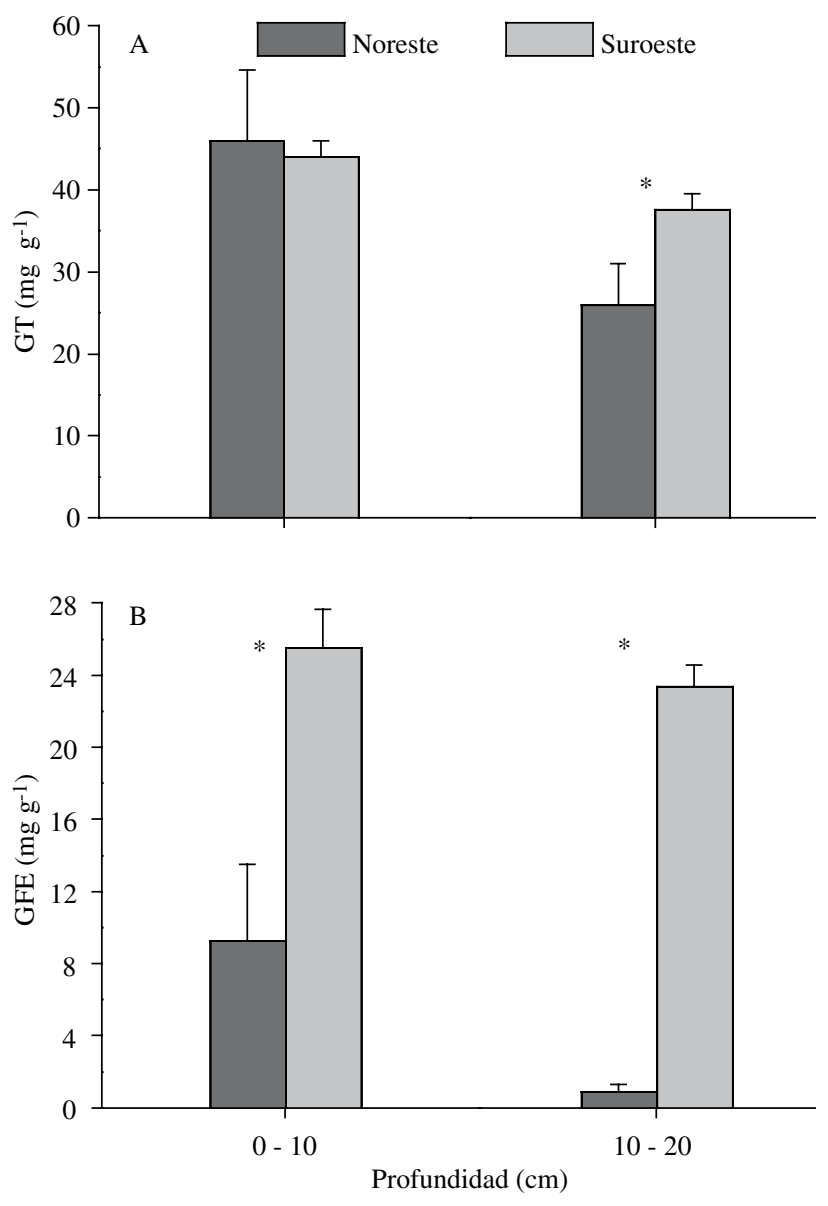

Figura 1. Contenido de glomalina total (GT) (A) y glomalina fácilmente extractable (GFE) (B) en Andisol del predio Rucamanque. (*) Presentan diferencias significativas $(P \leq 0,05)$. Línea vertical en la barra indica la desviación estándar.

Content of total glomalin (A) and easily extractable glomalin (B), in andisol of the Rucamanque forest. $P \leq 0.05$ significance. Vertical line in the bar indicates the standard deviation.

Cuadro 2. Proporción de C-G en el contenido total de carbono en el suelo andisol del predio Rucamanque.

Proportion of G-C in pool of total carbon in the andisol of the Rucamanque forest.

\begin{tabular}{crrrrr} 
Exposición & $\begin{array}{c}\text { Profundidad } \\
(\mathrm{cm})\end{array}$ & $\begin{array}{c}\mathrm{Cs}^{(1)} \\
\left(\mathrm{mg} \mathrm{g}^{-1}\right)\end{array}$ & $\begin{array}{c}\mathrm{GT}^{(2)} \\
\left(\mathrm{mg} \mathrm{g}^{-1}\right)\end{array}$ & $\begin{array}{c}\mathrm{C}-\mathrm{G} 2^{(3)} \\
\left(\mathrm{mg} \mathrm{g}^{-1}\right)\end{array}$ & $\begin{array}{c}\mathrm{C}-\mathrm{G} / \mathrm{Cs}^{(4)} \\
(\%)\end{array}$ \\
\hline NE & $0-10$ & 144,1 & 46,1 & 15,0 & 10,4 \\
$\mathrm{SO}$ & $0-10$ & 162,7 & 44,2 & 14,4 & 8,9 \\
$\mathrm{NE}$ & $10-20$ & 104,9 & 26,7 & 8,7 & 8,3 \\
$\mathrm{SO}$ & $10-20$ & 143,5 & 37,6 & 12,3 & 8,6 \\
\hline
\end{tabular}

(1) Contenido de carbono en el suelo. (2) Glomalina total. (3) Carbono glomalínico: $32 \%$ de carbono en la glomalina (P. Etcheverría, Doctorado en Ciencias de Recursos Naturales - Universidad de La Frontera, comunicación personal). ${ }^{(4)}$ Proporción de C-G en el contenido total de carbono en el suelo.
Características fúngicas. De las 13 especies arbóreas encontradas en los sitios de estudio presentaron colonización de HMA: olivillo, arrayán (Luma apiculata [DC.] Burret), lingue y tineo, lo que representa un $30 \%$ del total de especies arbóreas presentes en el dosel superior del bosque mixto adulto (cuadro 1). El sotobosque es muy denso por la abundante presencia de quila, especie que presenta colonización de HMA al igual que la mayoría de los arbustos; las raíces de las enredaderas presentaron colonización por HMA en su totalidad, mientras que las raíces de especies arbustivas como aromo de hoja pequeña (Azara microphylla Hook. f) y helechos del tipo calahuala (Polypodium feuillei Bertero) y seda de la luma (Hymenoglossum cruentum [Cav.] K. Presl) no estaban colonizadas por HMA (cuadro 3).

Cuadro 3. Especies del predio Rucamanque colonizadas por hongos micorrícico-arbusculares.

Plant species of an andisol from the Rucamanque forest colonized by mycorrhizal arbuscular fungi.

\begin{tabular}{|c|c|}
\hline Tipo de planta & Nombre científico \\
\hline Árbol & $\begin{array}{l}\text { Aextoxicon punctatum } \mathrm{R} \text {. et } \mathrm{P} . \\
\text { Luma apiculata (DC.) Burret } \\
\text { Persea lingue (R. et } \mathrm{P} \text {.) Nees ex Kopp. } \\
\text { Weinmannia trichosperma Cav. }\end{array}$ \\
\hline Arbusto & $\begin{array}{l}\text { Chusquea quila Kunth } \\
\text { Myrceugenia planipes (Hook. et Arn.) Berg. } \\
\text { Rhamnus diffusus Clos. }\end{array}$ \\
\hline Enredadera & $\begin{array}{l}\text { Cissus striata } \mathrm{R} \text {. et } \mathrm{P} . \\
\text { Elytropus chilensis }(\mathrm{A} . \mathrm{DC} \text {.) Muell. Arg. } \\
\text { Lapageria rosea } \mathrm{R} . \mathrm{et} \mathrm{P} . \\
\text { Luzuriaga radicans } \mathrm{R} \text {. et } \mathrm{P} . \\
\text { Mitraria coccinea } \text { Cav. }\end{array}$ \\
\hline Helecho & $\begin{array}{l}\text { Blechnum blechnoides Keyserl. } \\
\text { Blechnum hastatum Kaulf. }\end{array}$ \\
\hline Hierba & $\begin{array}{l}\text { Nertera granadensis (Mutis ex L.f.) Druce } \\
\text { Osmorrhiza chilensis H. et A. }\end{array}$ \\
\hline
\end{tabular}

El número de esporas de HMA encontradas en los suelos del bosque fue considerablemente mayor en los primeros centímetros de suelo superficiales, disminuyendo drásticamente entre los 10-20 cm, encontrándose diferencias respecto a las exposiciones del bosque en los suelos de la primera estrata $(P=0,034)$, no así en profundidad $(P=0,113)$ (figura $2 \mathrm{~A})$. Con respecto a la glomalina existe una estrecha relación entre la mayor cantidad de propágulos encontrados en el suelo con los niveles de proteína $(\mathrm{r}=0,84 ; P<0,001)$. El micelio total (figura 2C) mostró un descenso en la profundidad del suelo en ambas laderas al igual que el micelio activo, pese a no mostrar diferencias significativas entre las dos exposiciones. 

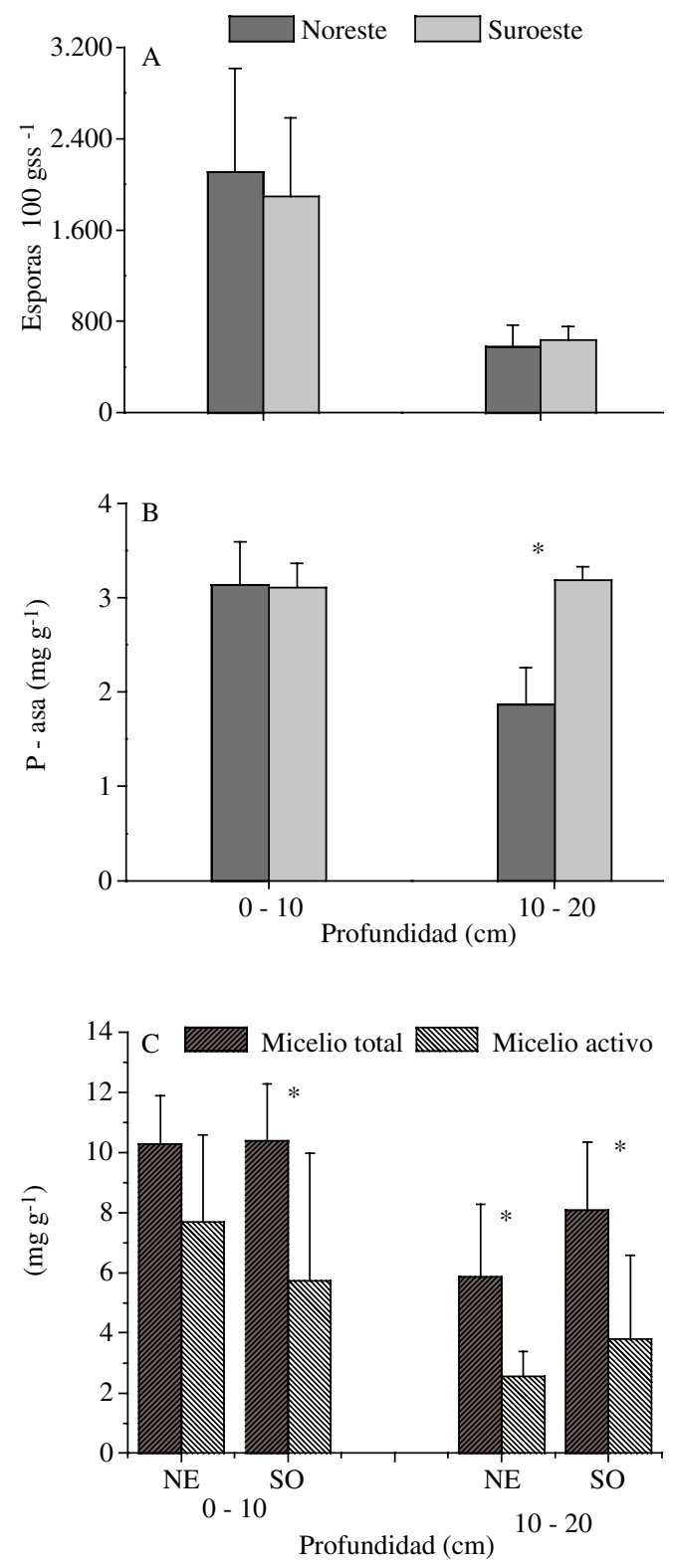

Figura 2. Parámetros fúngicos y enzimático en andisol del predio Rucamanque: esporas (A), actividad fosfatásica (B), micelio total y activo (C). (*) Presentan diferencias significativas $(P \leq 0,05)$. Línea vertical en la barra indica la desviación estándar.

Enzymatic and fungal parameters in andisol of the Rucamanque forest: spores (A); total mycelia (B) and phosphatase activity (C). (*) $P \leq 0.05$ significance. Vertical line in the bar indicates the standard deviation.

Características químicas del suelo. En profundidad no se encontraron diferencias significativas de $\mathrm{pH}$ entre $\mathrm{NE}$ y $\mathrm{SO}$ $(P=0,199)$ (figura 3A), mientras que en superficie los suelos del bosque con exposición NE fueron significativamente más ácidos $(P=0,035)$. La MO fue más abundante en los suelos superficiales, encontrándose diferencias significativas entre ambas exposiciones $(P=0,021)$, presentando la ladera SO un incremento de un $13 \%$ sobre la ladera NE (figura 3B). En profundidad, la MO disminuyó, encontrándose nuevamente mayor contenido en la ladera SO que en NE y presentando diferencias significativas entre ambas laderas $(P=0,001)$, con un promedio de carbono de 98 $\mathrm{Mg} \mathrm{ha}^{-1}$ en los primeros $20 \mathrm{~cm}$ del suelo. Los contenidos de aluminio de la primera y segunda estrata de suelo no fueron significativamente distintos entre sitios $(P=0,107$, $P=0,290$, respectivamente), aunque la tendencia fue de mayor nivel de aluminio en el suelo de la exposición SO (figura 3C).
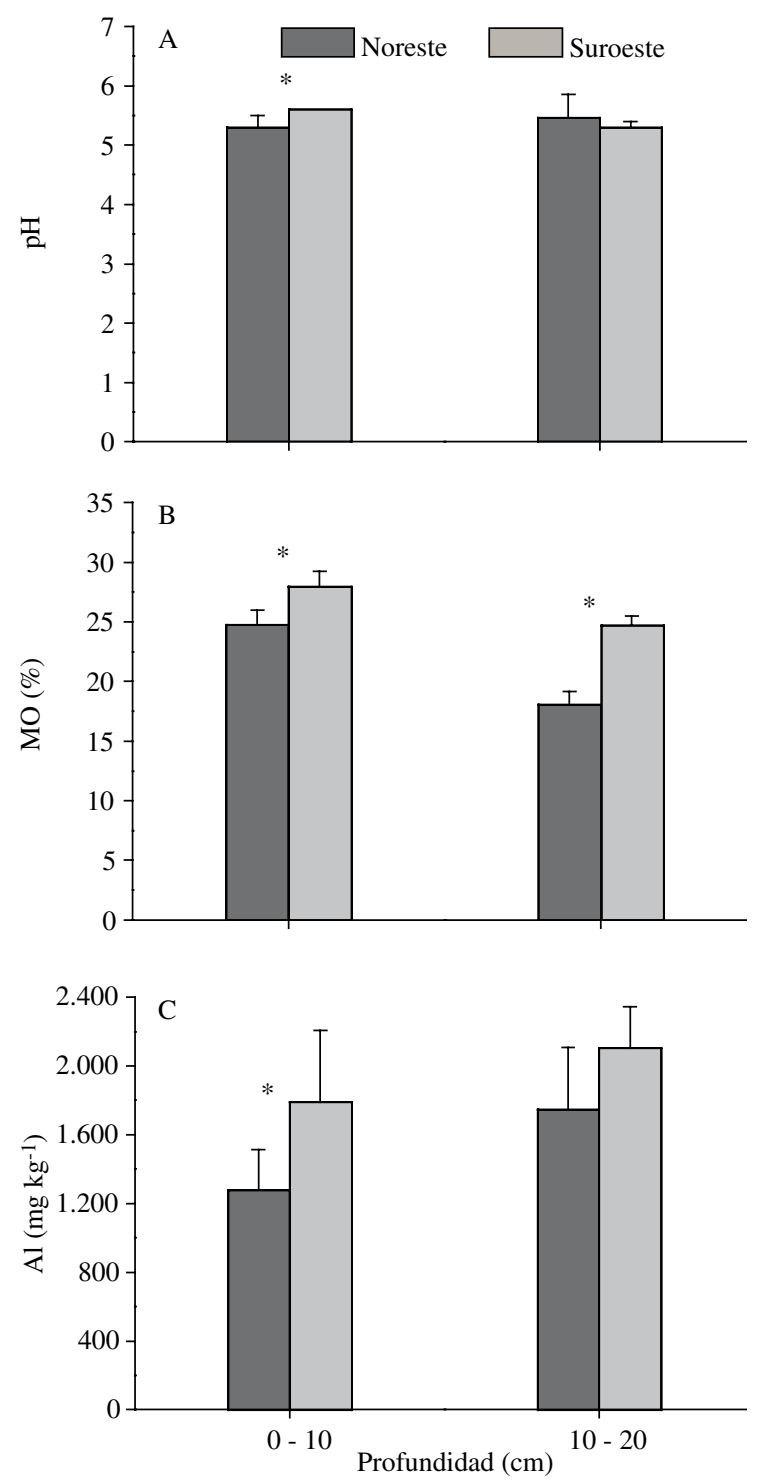

Figura 3. Características químicas del suelo: $\mathrm{pH}$ (A), \% materia orgánica (B) y aluminio extraíble $(\mathrm{C})$ en andisol del predio Rucamanque. $(*)$ Presentan diferencias significativas $(\mathrm{P} \leq 0,05)$. Línea vertical en la barra indica la desviación estándar.

Soil parameters: $\mathrm{pH}(\mathrm{A})$; \% MO (B); extractable aluminum (C) in an andisol of the Rucamanque forest. (*) $P \leq 0.05$ significance. Vertical line in the bar indicates the standard deviation. 
Los contenidos de P-disponible (figura 4A) variaron significativamente entre las dos áreas y en ambas estratas. Los mayores niveles de fósforo se observaron en la parte superficial del suelo con exposición SO, alcanzando una media de $17,9 \mathrm{mg} \mathrm{kg}^{-1}$, siendo significativamente superior $(P=0,028)$ a NE, que sólo presentó $1,1 \mathrm{mg} \mathrm{kg}^{-1}$ mientras que en el estrato $10-20 \mathrm{~cm}$ no se encontraron diferencias $(P=0,052)$. En superficie, el contenido de P-total del suelo fue mayor en el bosque con exposición SO, presentando diferencias significativas respecto a la exposición NE $(P=0,035)$, que se mantuvieron en profundidad $(P=0,015)$. En ambos sitios se encontró una alta correlación entre los niveles de P-total y P-disponible $(\mathrm{r}=0,74 ; P=0,001)$. La fracción orgánica de $\mathrm{P}(\mathrm{Po})$, húmico más fúlvico, se observó incrementada en la ladera $\mathrm{SO}$ y en el horizonte superficial del suelo, alcanzando niveles medios de $886,1 \mathrm{mg} \mathrm{kg}^{-1}$, lo que corresponde a un 58,8\% del P-total del suelo, no presentando diferencias con la ladera NE del bosque, la cual alcanzó un 55,8 \% del total $(P=0,083)$. En profundidad, en SO, el Po representó el 51,9\% del P-total, mostrando diferencias significativas $(P=0,035)$ con la ladera NE que sólo representó el 35,4\% del P-total. En ambos sitios de estudio la mayor fracción de Po correspondió a la forma P-húmico (forma de $\mathrm{P}$ más recalcitrante), siendo los contenidos de P-fúlvico bastante menores.

La actividad fosfatásica (figura 2B) en suelos superficiales fue algo superior en la exposición NE del bosque sin mostrar diferencias significativas con la ladera SO $(P=0,430)$; entre $10-20 \mathrm{~cm}$ hubo un incremento significativo en la ladera $\mathrm{SO}$ con respecto a NE.

$\mathrm{El}$ hierro (figura $5 \mathrm{~A}$ ) en la ladera $\mathrm{NE}$ fue significativamente menor que en SO tanto en superficie $(P=0,034)$ como en profundidad $(P=0,004)$. Así, en la exposición SO en la estrata superficial alcanzó $94,9 \mathrm{mg} \mathrm{kg}^{-1}$ directamente relacionado con la MO del sector, la que también presentó valores máximos $(\mathrm{r}=0,91, P<0,001)$. Los microelementos cobre y cinc tuvieron un comportamiento similar, presentando SO contenidos significativamente más elevados que NE. Así, entre 0-10 cm el cobre en SO tuvo un incremento de aproximadamente un $30 \%$ sobre NE, diferencia que se acentuó en profundidad (90\%). Los mayores niveles de cobre (figura 5B) se encontraron entre 10-20 cm con exposición SO, alcanzado la media de $3,6 \mathrm{mg} \mathrm{kg}^{-1}$. Entre ambas exposiciones, en la primera estrata, no se encontraron diferencias en manganeso $(P=0,163)$; por el contrario, en profundidad, donde los
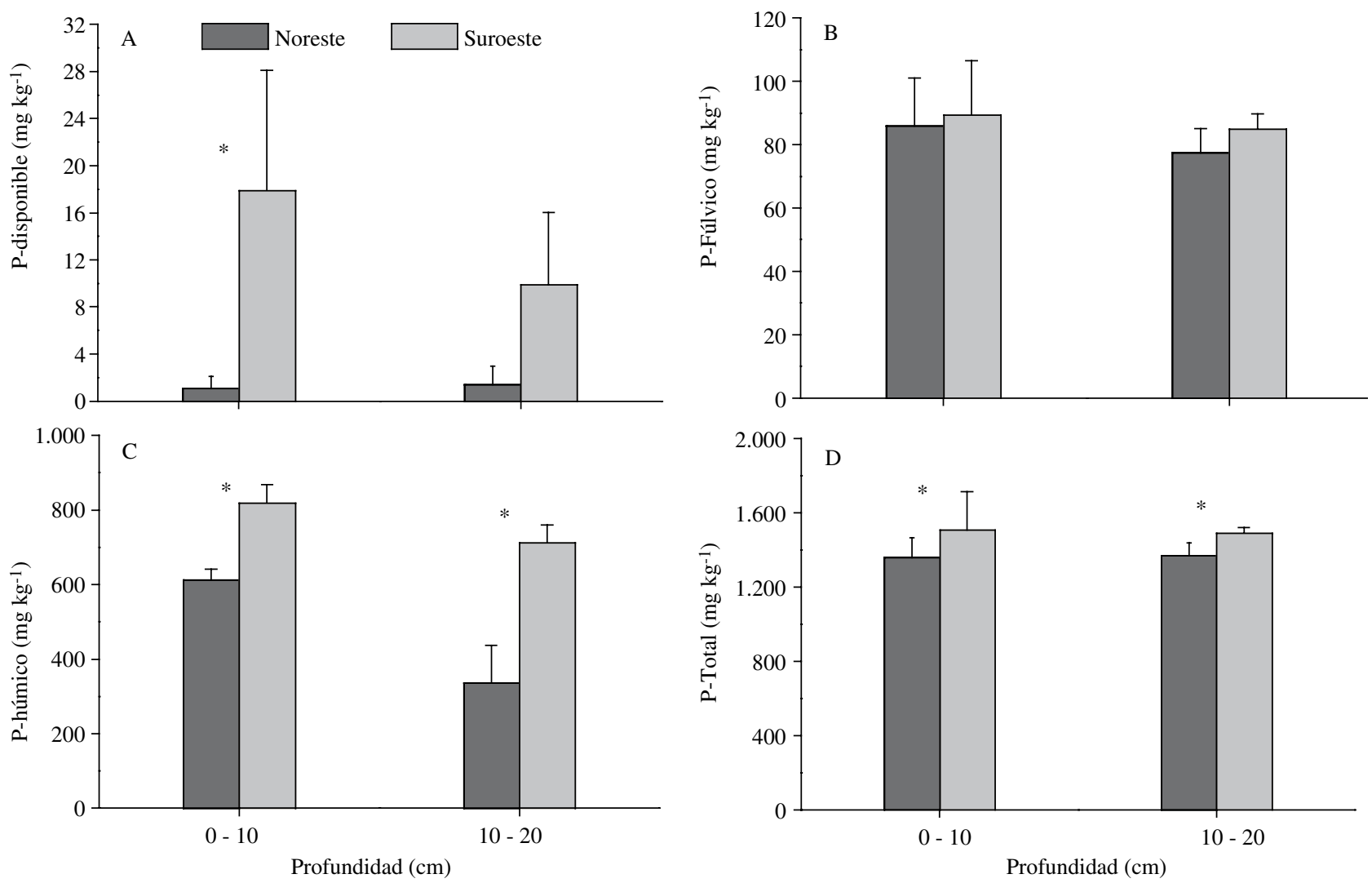

Figura 4. Fracciones de fósforo: P-disponible (A), P-fúlvico (B), P-húmico (C) y P-total (D) en andisol del predio Rucamanque.

(*) Presentan diferencias significativas $(P \leq 0,05)$. Línea vertical en la barra indica la desviación estándar.

Fractions of phosphorus: available-P (A); fulvic-P (B); humic-P (C) and total-P (D) in an andisol of the Rucamanque forest. $(*) P \leq 0.05$ significance. Vertical line in the bar indicates the standard deviation. 
niveles disminuyeron en ambas laderas, se encontraron diferencias entre ambos sitios $(P=0,004)$, siendo el suelo del bosque con exposición NE el que presentó menor contenido de manganeso.

La glomalina con la MO tuvo una alta relación, así como también con el Po, hierro, cinc y manganeso, parámetros que explicarían los contenidos de glomalina (cuadro 4). Sin embargo, no se observó relación con el pH, P-disponible, P-total, aluminio y cobre. Los parámetros químicos que correlacionaron con la glomalina fueron los mismos (a excepción del hierro) relacionados con parámetros fúngicos, mostrando la estrecha relación entre la glomalina total y el número de esporas $(\mathrm{r}=0,84 ; P<0,001)$. Además, una alta correlación se obtuvo entre COS y el C-G $(r=0,83)$. Los contenidos de MO se relacionaron con la disponibilidad de cobre $(\mathrm{r}=0,56 ; P=0,025)$ y cinc $(\mathrm{r}=0,91 ; P<0,001)$. Así también los valores de hierro correlacionaron estrechamente con la presencia cobre $(\mathrm{r}=0,63 ; P=0,009)$, cinc $(\mathrm{r}=0,86 ; P<0,001)$ y manganeso $(\mathrm{r}=0,76 ; P<0,001)$.
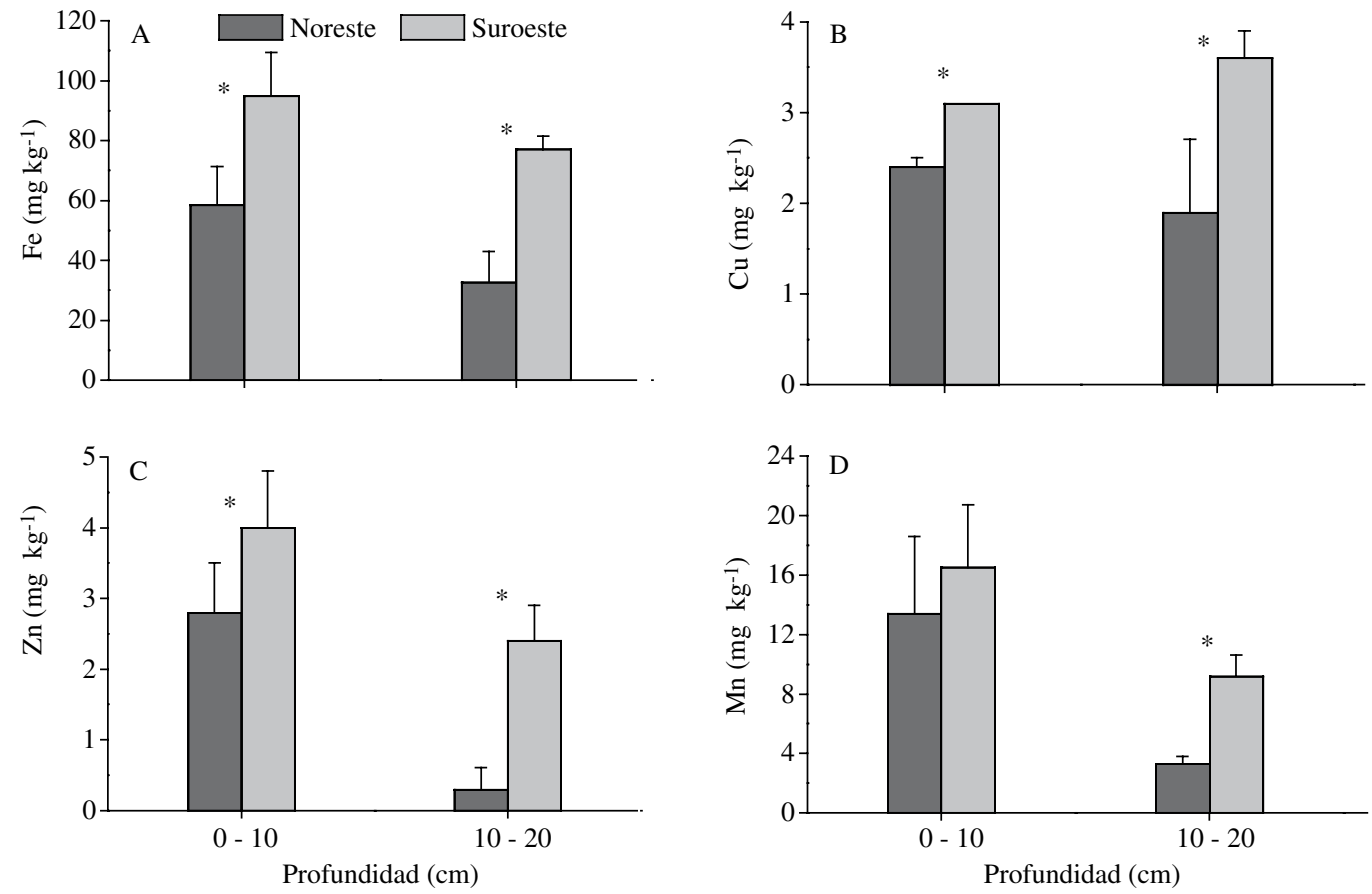

Figura 5. Microelementos del suelo: hierro (A), cobre (B), cinc (C) y manganeso (D) en andisol del predio Rucamanque. (*) Presentan diferencias significativas $(P \leq 0,05)$. Línea vertical en la barra indica la desviación estándar.

Soil microelements of the soil: iron (A); copper (B); zinc (C); manganese (D) in an andisol of the Rucamanque forest. $(*) P \leq 0.05$ significance. Vertical line in the bar indicates the standard deviation.

Cuadro 4. Contenido de glomalina total y número de esporas HMA (Y) en relación con características químicas del suelo (X) en el predio Rucamanque $(n=16)$.

Relationships between total glomalin and AMF spores (Y) with soil chemical characteristics $(X)$ at Rucamanque forest $(n=16)$.

\begin{tabular}{llll}
\hline $\mathrm{Y}$ & $\mathrm{X}$ & Regresión lineal & $\mathrm{r}^{(1)}$ \\
\hline Glomalina total $\left(\mathrm{mg} \mathrm{g}^{-1}\right)$ & $\mathrm{MO}(\%)$ & $\mathrm{Y}=7,7+1,94 \mathrm{X}$ & $0,83^{* * *}$ \\
Glomalina total $\left(\mathrm{mg} \mathrm{g}^{-1}\right)$ & $\mathrm{P}$-orgánico $\left(\mathrm{mg} \mathrm{kg}^{-1}\right)$ & $\mathrm{Y}=13,6+0,034 \mathrm{X}$ & $0,69^{* *}$ \\
Glomalina total $\left(\mathrm{mg} \mathrm{g}^{-1}\right)$ & $\mathrm{Fe}\left(\mathrm{mg} \mathrm{kg}^{-1}\right)$ & $\mathrm{Y}=22,5+0,25 \mathrm{X}$ & $0,70^{* *}$ \\
Glomalina total $\left(\mathrm{mg} \mathrm{g}^{-1}\right)$ & $\mathrm{Zn}\left(\mathrm{mg} \mathrm{kg}^{-1}\right)$ & $\mathrm{Y}=26,7+5 \mathrm{X}$ & $0,80^{* * *}$ \\
Glomalina total $\left(\mathrm{mg} \mathrm{g}^{-1}\right)$ & $\mathrm{Mn}\left(\mathrm{mg} \mathrm{kg}^{-1}\right)$ & $\mathrm{Y}=25,9+1,2 \mathrm{X}$ & $0,79^{* * *}$ \\
Número de esporas $\left(\mathrm{N}^{\mathrm{o}} 100 \mathrm{gss}^{-1}\right)$ & $\mathrm{MO}(\%)$ & $\mathrm{Y}=-1.849+132 \mathrm{X}$ & $0,57^{*}$ \\
Número de esporas $\left(\mathrm{N}^{\mathrm{o}} 100 \mathrm{gss}^{-1}\right)$ & $\mathrm{P}$-orgánico $\left(\mathrm{mg} \mathrm{kg}^{-1}\right)$ & $\mathrm{Y}=-783+2,87 \mathrm{X}$ & $0,59^{*}$ \\
Número de esporas $\left(\mathrm{N}^{\mathrm{o}} 100 \mathrm{gss}^{-1}\right)$ & $\left.\mathrm{Zn}(\mathrm{mg} \mathrm{kg})^{-1}\right)$ & $\mathrm{Y}=432,3+365,9 \mathrm{X}$ & $0,60^{*}$ \\
Número de esporas $\left(\mathrm{N}^{\mathrm{o}} 100 \mathrm{gss}^{-1}\right)$ & $\mathrm{Mn}\left(\mathrm{mg} \mathrm{kg}^{-1}\right)$ & $\mathrm{Y}=305,7+94,4 \mathrm{X}$ & $0,63^{*}$ \\
\hline
\end{tabular}

${ }^{1}$ Coeficiente de regresión. $* P<0,05, * * P<0,01, * * * P<0,001$. 


\section{DISCUSIÓN}

Los contenidos de GT encontrados en Rucamanque son menores a los informados por Morales et al. (2005) en un andisol bajo bosque siempreverde de la precordillera en la Región de Los Ríos, quienes encontraron valores de 98 mg $\mathrm{g}^{-1}$ a una profundidad de $0-10 \mathrm{~cm}$. Esta diferencia en los contenidos de glomalina probablemente es consecuencia del menor número de hospederos que presentaron asociaciones del tipo micorriza arbuscular en el ecosistema boscoso de Rucamanque, con el consiguiente descenso en la cantidad de propágulos de HMA presentes en el suelo responsables de la producción de la glicoproteína. La disminución en los contenidos de glomalina a través del perfil del suelo concuerda con lo informado por Borie et al. (2000) en un alfisol de la Región del Bío Bío y con Rillig et al. (2003) en suelos agrícolas y forestales de Ohio (EE.UU.), quienes han puesto en evidencia que la glomalina no sólo se encuentra presente en el horizonte superficial sino que también en profundidad. La disminución de la glomalina estaría relacionada a bajos contenidos de MO y a una disminución en los propágulos fúngicos, principalmente esporas y micelio, como informan Castillo et al. (2006) en suelos forestales de un bosque siempreverde de la Región de Los Ríos. Por el contrario, en un ultisol de un agroecosistema de la Región de la Araucanía con manejo conservacionista con rotación corta de trigo (Triticum aestivum L.) - avena (Avena sativa L.), la GT fluctúa entre 8,74 y 9,24 $\mathrm{mg} \mathrm{g}^{-1}$ en los suelos superficiales mientras en profundidad el rango informado varía de 6,61 a 6,77 mg $\mathrm{g}^{-1}$ (Morales et al. 2005). Estos antecedentes sugerirían que los niveles de glomalina en ecosistemas forestales serían superiores al de los agrosistemas, posiblemente debido al incremento en la velocidad de descomposición de los diversos propágulos de HMA presentes en los suelos bajo bosque, proceso responsable de la llegada de la glomalina a la fracción humina del suelo (Driver et al. 2005). La mayor proporción de GFE en la ladera SO y el incremento de glomalina recalcitrante en NE, áreas que presentan una vegetación muy similar, mostraría el efecto neto de la exposición y la pendiente sobre las fracciones de glomalina. Las laderas con orientación NE corresponden a zonas más secas y cálidas, no así SO que resulta más sombría y húmeda. Según Irizarri y Mendía (1991) suelos de laderas con exposición Sur presentan una mayor profundidad de desarrollo que los suelos más secos de laderas con exposición Norte, mientras las laderas con orientación Este protegidas del viento presentan suelos más profundos que las de exposición Oeste. La ladera NE, con una pendiente de aproximadamente un 30\%, tuvo mayor porcentaje en GT, mientras el área SO, con una pendiente abrupta sobre $60 \%$, presentó un mayor contenido en GFE.

Los altos niveles de óxidos de hierro y aluminio que poseen estos suelos posiblemente influyen en la recalcitrancia que presenta la glicoproteína y de aquí que los niveles encontrados en Rucamanque resultan elevados, lo que asociado a mayores contenidos de humina que presentan los suelos derivados de cenizas volcánicas conlleva a que el carbono y nitrógeno asociados a la glomalina pudieran ser cualitativa y cuantitativamente más importantes que el carbono y nitrógeno provenientes de los ácidos húmicos y fúlvicos que se perderían con las huminas al realizar el fraccionamiento tradicional (Borie et al. 2002). Recientes investigaciones informan que, si bien el carbono asociado a las fracciones húmicas de la $\mathrm{MO}$ es mayor que el carbono proveniente de la glomalina, la proporción de la glicoproteína en el suelo es hasta nueve veces superior en comparación a la de ácidos húmicos y fúlvicos. En el caso de nitrógeno la glomalina presenta la mayor parte del elemento en comparación con las otras fracciones de MO, pero en conjunto sólo representa el $31 \%$ del total de nitrógeno en el suelo (Nichols y Wright 2006). En el predio Rucamanque, la alta correlación entre COS y el C-G sugiere un elevado nivel de recalcitrancia de la glicoproteína.

En el bosque mixto del predio Rucamanque coexisten asociaciones del tipo micorriza ectotrófica con micorrizas arbusculares (MA); según lo informado por Torti y Coley (1999) en bosques tropicales la asociación ectomicorrícica no es una monodominancia, sino que existe una codominancia con especies vegetales que forman MA. Según Moyersoen et al. (2001) esta coexistencia en los sistemas boscosos de ectomicorrizas y MA se debe a que los hongos ocuparían distintos nichos en el ecosistema. Además, Lovelook y Miller (2002) informan que cuando un ecosistema boscoso se encuentra dominado con vegetación asociada principalmente con hongos ectomicorrícicos el potencial de inóculo de HMA aumenta. Así, en el sotobosque especies de plantas con MA pueden sobrevivir la competencia con plantas ectomicorrícicas, probablemente debido a que las raíces de las plantas con MA podrían conectarse mediante redes fúngicas transportando carbohidratos a plantas con desventajas fotosintéticas (Leake et al. 2004).

La densidad de esporas de HMA encontradas en Rucamanque resultó baja si se compara con un andisol de bosque siempreverde en la Región de Los Ríos (Castillo et al. 2006). Esta baja cantidad de propágulos fúngicos en las dos áreas de estudio estaría relacionada con una menor riqueza de especies arbóreas y del sotobosque que forman asociaciones del tipo MA. Sin embargo, la densidad de esporas del predio Rucamanque resulta mayor a las encontradas en un bosque caducifolio de roble ubicado en el cordón montañoso central de la Región de Los Ríos y con presencia mayoritaria de Nothofagus obliqua, especie ectomicorrícica y con una baja diversidad de especies acompañantes que forman micorrizas arbusculares (Carrillo et al. 1992).

Los suelos forestales, en general, son bastante ácidos; sin embargo, los niveles de acidez observados en Rucamanque se encuentran dentro de los rangos normales para suelos de bosques nativos de estas latitudes (Sadzawka et al. 1995). Bürgmann (1998) informa que el pH de los suelos del 
sector fluctúa entre 4,9 y 5,0; mientras que Carrillo et al. (1992) encontraron $\mathrm{pH}$ entre 5,1 y 5,8 en andisoles bajo formaciones boscosas caducifolias templadas de $N$. obliqua (Asociación Nothofago-Perseetum). En los ecosistemas forestales la acidez es una consecuencia de los elevados contenidos de MO, por formación de ácidos húmicos y fúlvicos, principalmente de los primeros (Fernández 1993). Suelos ácidos con pH inferior a 5,0 muestran acumulación de MO ya que la acidez incide en la cantidad y composición de los microorganismos al disminuir la eficiencia de la mineralización (Sombroek 1966).

Los niveles de MO de Rucamanque resultaron mayores a otros suelos trumaos bajo bosque nativo adulto; así, por ejemplo, la MO bajo bosque adulto de $N$. obliqua en la Depresión Intermedia de la Región de Los Ríos alcanza un 20\% (Carrillo et al. 1992). Resultados parecidos se obtuvieron en andisoles ubicados en la precordillera de la Región de Los Lagos, con bosques siempreverdes del tipo forestal Coigüe-Raulí-Tepa, alcanzando un $22 \%$ (Castillo et al. 2006).

Entre los factores que limitan el crecimiento de las plantas en los suelos ácidos se encuentran la toxicidad por aluminio y la reducción en la disponibilidad de fósforo por precipitación de fosfato de aluminio, efectos que generalmente están asociados (Baligar et al. 1993). El estrato más superficial de la exposición SO presentó la mayor disponibilidad de fósforo, mostrando que al avanzar en estratas más profundas disminuye la capacidad de adsorción y disponibilidad del elemento (Gianzo y Pizarro 2000). La escasa disponibilidad de fósforo en NE concuerda con cifras del orden de $3,5 \mathrm{mg} \mathrm{kg}^{-1}$ informadas por Carrillo et al. (1992) en bosques caducifolios de roble en el cordón montañoso central de la Región de Los Ríos. En los suelos con baja disponibilidad de fósforo las plantas micorrícicas presentan mayores tasas de crecimiento que las plantas no micorrizadas; por el contrario, con altos niveles de fósforo soluble la dependencia micorrícica del hospedero disminuye (Smith y Gianinazzi-Pearson 1988). Así, en la ladera SO se observó una disminución de propágulos fúngicos al aumentar la disponibilidad del nutriente. Los resultados de Po son corroborados por antecedentes de la literatura que estiman sobre un 50\% el aporte del Po al P-total (Richardson 2001). La mayor parte del P-total se encuentra en la MO como inositol fosfatos, nucleótidos y fosfolípidos; sin embargo, son los iones fosfato las formas de fósforo asimiladas por microorganismos y plantas, los que son liberados como consecuencia de la mineralización del Po. Estos procesos son catalizados por fosfatasas, enzimas del suelo que son liberadas por microorganismos y raíces de plantas (Rao et al. 1996).

Finalmente, cabe destacar en términos generales los elevados niveles de fertilidad que poseen los suelos estudiados. Así, los contenidos en materia orgánica, fósforo disponible y Po fácilmente mineralizable, conjuntamente con los valores de $\mathrm{pH}$ y micronutrientes cobre, cinc, manganeso y hierro, los hacen equivalentes a buenos suelos agrícolas tanto en sus estratas superficiales como en profundidad.

Especial relevancia poseen los contenidos en microelementos disponibles, toda vez que existen escasos antecedentes sobre estos nutrientes en suelos forestales bajo bosques caducifolios. No obstante, sus valores son significativamente menores que los observados en un bosque laurifolio (Reserva Fray Jorge) en la Región de Coquimbo (Fernández 2004).

\section{CONCLUSIONES}

Las especies acompañantes del bosque mixto adulto de Rucamanque que presentan micorrizas arbusculares representan un 30\% del estrato arbóreo, mientras que en el sotobosque la colonización por HMA fue mayoritaria, tanto en el estrato arbustivo como en el herbáceo. En general, el suelo presentó buenos niveles de fertilidad incluyendo una alta cantidad en COS.

La exposición NE, con pendiente suave, presentó el mayor contenido de la fracción recalcitrante de glomalina, mientras la ladera SO, de pendiente abrupta, tuvo la mayor fracción de glomalina fácilmente extraíble, y el C-G representó una fracción importante dentro del COS. No obstante, en ambas laderas el carbono asociado a glomalina comprende un 8,9 a $10,4 \%$ del carbono total del horizonte superficial, encontrándose una alta correlación entre COS y C-G.

El suelo de las dos áreas de estudio mostró una alta cantidad de propágulos HMA, en especial esporas, las cuales correlacionaron estrechamente con la glomalina depositada en el suelo, a pesar de ser un ecosistema dominado preferentemente por ectomicorrizas.

\section{AGRADECIMIENTOS}

Este estudio fue parcialmente financiado por el Proyecto Fondecyt 1060372.

\section{REFERENCIAS}

Baligar V, R Schaffert, H Dos Santos, G Pitta, C Bahía Filho. 1993. Soil aluminum effects on uptake, influx, and transport of nutrients in sorghum genotypes. Plant and Soil 150: 271-277.

Blevins R, M Smith, G Thomas. 1984. Changes in soil properties under no-tillage. In Phillips R, S Phillips eds. No-tillage agriculture, principles and practices. New York, USA. Van Nostrand Reinhold Company. p. 190-230.

Borie, F, R Rubio. 1999. Effects of arbuscular-mycorrhizae and liming on growth and mineral acquisition of aluminumtolerant and aluminum-sensitive barley cultivars. J. Plant Nutr. 22: 121-137.

Borie F, R Rubio, A Morales, C Castillo. 2000. Relación entre densidad de hifas de hongos micorrizógenos arbusculares 
y producción de glomalina con las características físicas y químicas de suelos bajo cero labranza. Rev. Chil. Hist. Nat. 73: 749-756.

Borie G, P Peirano, H Zunino, S Aguilera. 2002. N-pool in volcanic ash-derived soils in Chile and its changes in deforested soils. Soil Biol. Biochem. 34: 1201-1206.

Borie F, R Rubio. 2003. Total and organic phosphorus in Chilean volcanic soils. Gayana Botanica 60: 69-78.

Borie F, R Rubio, J Rouanet, A Morales, G Borie, C Rojas. 2006. Effect of tillage systems on soil characteristics, glomalin and mycorrhizal propagules in a Chilean Ultisol. Soil \& Tillage Res. 88: 253-261.

Bürgmann H. 1998. Soil quality changes under Pinus radiata plantations in the IXth Region of Chile; applicability of soil microbial activity and nutrient analysis for the evaluation of sustainability. Diplomarbeit. Bayreuth, Alemania. Universität Bayreuth. 128 p.

Carrillo R, R Godoy, H Peredo. 1992. Simbiosis micorrícica en comunidades boscosas del Valle Central en el sur de Chile. Bosque 13(2): 57-67.

Castillo CG, F Borie, R Godoy, R Rubio, E Sieverding. 2006. Diversity of mycorrhizal plant species and arbuscular mycorrhizal fungi in evergreen forest, deciduous forest and grassland ecosystems of Southern Chile. J. Appl. Bot. Food Quality 80: 40-47.

Di Castri F, E Hajek. 1976. Bioclimatología de Chile. Santiago, Chile. Universidad Católica de Chile. 128 p.

Dick W, M Tabatabai. 1977. An alkaline oxidation method for determination of total phosphorus in soils. Soil Sci. Soc. Am. J. 41: 511-514.

Donoso C. 1981. Tipos forestales de los bosques nativos de Chile. Santiago, Chile. Proyecto Investigación y Desarrollo Forestal FO: DP/CHI/76/003. Documento de trabajo $\mathrm{N}^{\mathrm{o}} 38.70 \mathrm{p}$.

Donoso C. 1995. Bosques templados de Chile y Argentina. Variación, estructura y dinámica. Santiago. Chile. Editorial Universitaria. Tercera Edición. 380 p.

Driver J, W Holben, M Rillig. 2005. Characterization of glomalin as a hyphal wall component of arbuscular mycorrhizal fungi. Soil Biol. Biochem. 37: 101-106.

Frank D, M Finckh. 1998. Vegetation dynamics of deciduous Nothofagus forest in southern Chile. Temuco, Chile. Project Ecosystem of the IX Región of Chile: Influence of land use on sustainability. Final Report. UBT/UFRO/UACH/ IACR. 220 p.

Fernández I. 1993. Determinação das fraçoes humicas e fulvicas extraídas com pirofosfato de sodio a diferentes valores de $\mathrm{pH}$ em tres solos brasileiros. In XXIV Congresso Brasileiro de Ciencia do Solo. Resumos Vol I. Goiania. Goias. Brasil. Sociedade Brasileira da Ciencia do Solo. p. 157-158.

Fernández I. 2004. Caracterización química de los suelos del Bosque de Fray Jorge (capítulo 15). In Squeo FA, JR Gutiérrez, IR Hernández, eds. Historia Natural del Parque Nacional Bosque Fray Jorge. La Serena, Chile. Ediciones Universidad de La Serena. p. 265-279.

Gianzo J, Y Pizarro. 2000. Dinámica de fósforo en muestras de suelos del Parque Nacional Bosque Fray Jorge. Tesis de Licenciatura en Química. La Serena, Chile. Universidad de La Serena. 94 p.

Irizarri J, J Mendía. 1991. Reconocimiento de suelos y evaluación de la aptitud forestal de la región precordillerana de la provincia de Río Negro. Cinco Saltos, Río Negro, Argentina. Consejo Federal de Inversiones - Universidad Nacional del Comahue. $61 \mathrm{p}$.

Jandl R. 2001. Medición de tendencias en el tiempo del almacenamiento de carbono del suelo. In Simposio Internacional Medición y Monitoreo de la Captura de Carbono en Ecosistemas Forestales. Valdivia, Chile. Universidad Austral de Chile. 12 p.

Jeffries P, S Gianinazzi, S Perotto, K Turnau, JM Barea. 2003. The contribution of arbuscular mycorrhizal fungi in sustainable maintenance of plant health and soil fertility. Biol. Fertil. Soils 37: 1-16.

Leake J, D Johnson, D Donnelly, G Muckle, L Boddy, D Read. 2004. Networks of power and influence: the role of mycorrhizal mycelium in controlling plant communities and agroecosystem functioning. Can. J. Bot. 82: 1016-1045.

Lindsay W, W Norvell. 1978. Development of DTPA test for Zinc, Iron, Manganese and Copper. Soil Sci. Soc. Amer. 42: 421-425.

Lovelook C, R Miller. 2002. Heterogeneity in inoculum potencial and effectiveness of arbuscular mycorrhizal fungi. Ecology 83: 823-832.

Lynch J, J Whipps. 1990. Substrate flow in the rhizosphere. Plant Soil. 129: 1-10.

Marticorena C, M Quezada. 1985. Catálogo de la flora vascular de Chile. Gayana 42: 1-157.

Martínez A. 1999. Silvicultura práctica en renovales puros y mixtos y bosques remanentes originales del tipo forestal Roble - Raulí - Coigüe. In C Donoso, A Lara eds. Silvicultura de los bosques nativos de Chile. Santiago, Chile. Editorial Universitaria. p. 145-175.

Mendoza J, F Borie. 1998. Effect of Glomus etunicatum inoculation on aluminum, phosphorus, calcium, and magnesium uptake of two barley genotypes with different aluminum tolerance. Commun. Soil Sci. Plant Anal. 29: 5-6.

Morales A, CG Castillo, R Rubio, F Borie, JL Rouanet. 2005. Niveles de glomalina en suelos de dos ecosistemas del sur de Chile. R. C. Suelo Nutr. Vegetal. 5(1): 37-45.

Moyersoen B, P Becker, I Alexander. 2001. Are ectomycorrhizas more abundant than arbuscular mycorrhizas in tropical heath forest? New. Phytol. 150: 591-599.

Newsham K, A Fitter, A Watterson. 1995. Arbuscular mycorrhiza protect an annual grass from root pathogenic fungi in the field. J. Ecol. 3: 991-1000.

Nichols K. 2003. Characterization of glomalin, a glycoprotein produced by arbuscular mycorrhizal fungi. $\mathrm{Ph} \mathrm{D}$ Thesis Natural Resource Sciences. College Park, Maryland, USA. University of Maryland. $285 \mathrm{p}$.

Nichols K, S Wright. 2006. Carbon and nitrogen in operationally defined soil organic matter pools. Biol. Fertil. Soils (2): 215-220.

Olsen S, L Sommers. 1982. Phosphorus. In Page A, R Miller, D Keeney eds. Methods of soil analysis, part 2. Chemical and microbiological properties. (Agronomy Monograph $\mathrm{n}^{\circ}$ 9). Madison, Wis., USA. Am. Soc. Agron. Soil Sci. Soc. p. 403- 430.

Pawlowska T, I Charvat. 2004. Heavy-metal stress and developmental patterns of arbuscular mycorrhizal fungi. Appl Environ. Microbiol. 70: 6643-6649.

Phillips J, D Hayman. 1970. Improved procedures for clearing roots and staining parasitic and vesicular-arbuscular mycor- 
rhizal fungi for rapid assessment of infection. Trans. Br. Mycol. Soc. 55: 159-161.

Rao M, L Gianfreda, F Palmiero, A Violante. 1996. Interactions of acid phosphatase with clays, organic molecules and organo-mineral complexes. Soil Sci. 161: 751-760.

Richardson A. 2001. Prospects for using soil microorganisms to improve the acquisition of phosphorus by plants. Aust J Plant Physiol 28: 897-906.

Rillig M, S Wright, M Allen, C Field. 1999. Rise in carbon dioxide changes soil structure. Nature 400: 628.

Rillig M, S Wright, K Nichols, W Shmith, M Torn. 2001. Large contributions of arbuscular mycorrhizal fungi to soil carbon pools in tropical forest soils. Plant Soil. 233: 167-177.

Rillig M, P Ramsey, S Morris, E Paul. 2003. Glomalin, an arbuscular-mycorrhizal fungal soil protein, responds to soil-use change. Plant Soil 253(2): 293-299.

Rubio R, E Moraga, F Borie. 1990. Acid phosphatase activity and vesicular-arbuscular infection associated with roots of four wheat cultivars. J. Plant Nutr. 13: 585-598.

Rubio R, F Borie, C Schalchli, C Castillo, R Azcón. 2003. Occurrence and effect of arbuscular mycorrhizal propagules in wheat as affected by the source and amount of phosphorus fertilizer and fungal inoculation. Appl. Soil Ecol. 23: 245-255.

Ruíz-Lozano J, R Azcón. 1995. Hyphal contribution to water uptake in mycorrhizal plants as affected by the fungal species and water status. Physiol. Plant. 95: 472-478.

Sadzawka A, M Peralta, M Ibarra, J Peralta, J Fuentes. 1995. Características químicas de los suelos forestales chilenos. Bosque 16(1): 9-28.

Sadzawka A, R Grez, M Mora, N Saavedra, M Carrasco, C Rojas. 2000. Métodos de análisis recomendados para los suelos chilenos. Comisión de Normalización y Acreditación. Santiago, Chile. Sociedad Chilena de la Ciencia del Suelo. 62 p.
Salas C. 2001. Caracterización básica del relicto de biodiversidad Rucamanque. Bosque Nativo 29: 3-9.

Schindler F, E Mercer, J Rice. 2007. Chemical characteristics of glomalin-relatad soil protein (GRSP) extracted from soils of varying organic matter content. Soil Boil. Biochem. 39: $320-329$.

Sieverding E. 1991. Vesicular-arbuscular mycorrhiza management in tropical agrosystems. GTZ, Eschborn, Germany. 371 p.

Smith S, V Gianinazzi-Pearson. 1988. Physiological interactions between symbionts in vesicular-arbuscular mycorrhizal plants. Annu. Rev. Plant Physiol. Plant Mol. Biol. 39: 221-244.

Sombroek W.G. 1966. Amazon Soils, a reconnaissance of the soils of the Brazilian Amazon. Wageningen, The Netherlands. PUDOC. 292 p.

Tabatabai M, J Bremmer. 1969. Use of P-nitrophenyl phosphate for assay of soil phosphatase activity. Soil Biol. Biochem. 1:301-307.

Torti S, P Coley. 1999. Tropical monodominance: a preliminary test of the ectomycorrhizal hypothesis. Biotropica. 31: 220-228.

van der Heijden M, J Klironomos, M Ursic, P Moutoglis, R Streitwolf-Engel, T Boller, A Wiemken, I Sanders. 1998. Mycorrhizal fungal diversity determines plant biodiversity, ecosystem variability, and productivity. Nature 396: 69-72.

Walkley A, I Black. 1934. An examination of the Degtjareff method for determining soil organic matter and the proposed modification of the chromic acid titration method. Soil Sci. 37: 29-38.

Wright S, A Upadhyaya. 1996. Extraction of an abundant and unusual protein from soil and comparison with hyphal protein of arbuscular mycorrhizal fungi. Soil Sci. 161: 575-586. 